\title{
Nucleophilic Aromatic Substitution on Aryl-Amido Ligands Promoted by Oxidizing Osmium(IV) Centers
}

\author{
Jake D. Soper, Erik Saganic, David Weinberg, David A. Hrovat, \\ Jason B. Benedict, ${ }^{+}$Werner Kaminsky, ${ }^{+}$and James M. Mayer ${ }^{*}$ \\ Department of Chemistry, Campus Box 351700 \\ University of Washington, Seattle WA 98195-1700
}

\section{Supporting Information}

Figure S1. Overlay plot of optical spectra of a kinetic experiment.

Figure S2. Optical spectra

Figure S3. Plot of $k_{\text {obs }}$ vs. [pyrrolidine] at 25,45 , and $55^{\circ} \mathrm{C}$. 


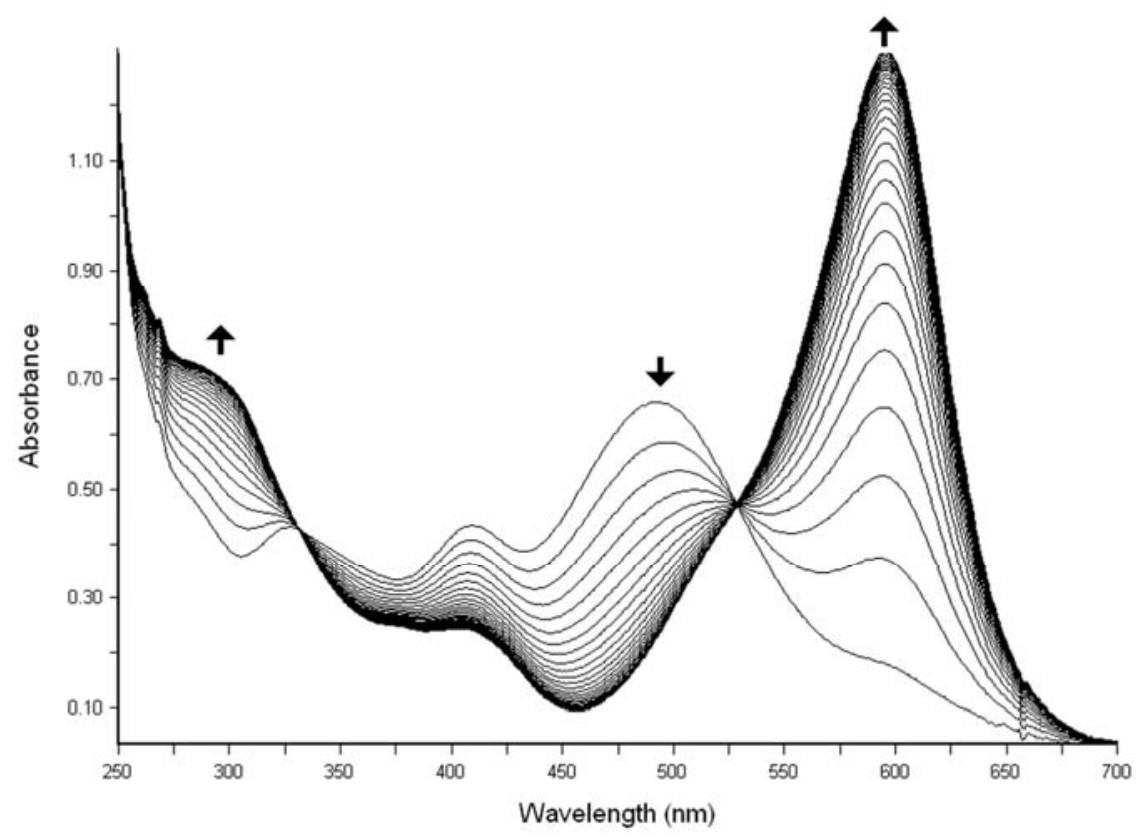

Figure S1. Spectral changes from reaction of $\mathrm{TpOs}(\mathrm{NHPh}) \mathrm{Cl}_{2}(\mathbf{1})$ with pyrrolidine in $\mathrm{CH}_{3} \mathrm{CN}$ at $298 \mathrm{~K}$.

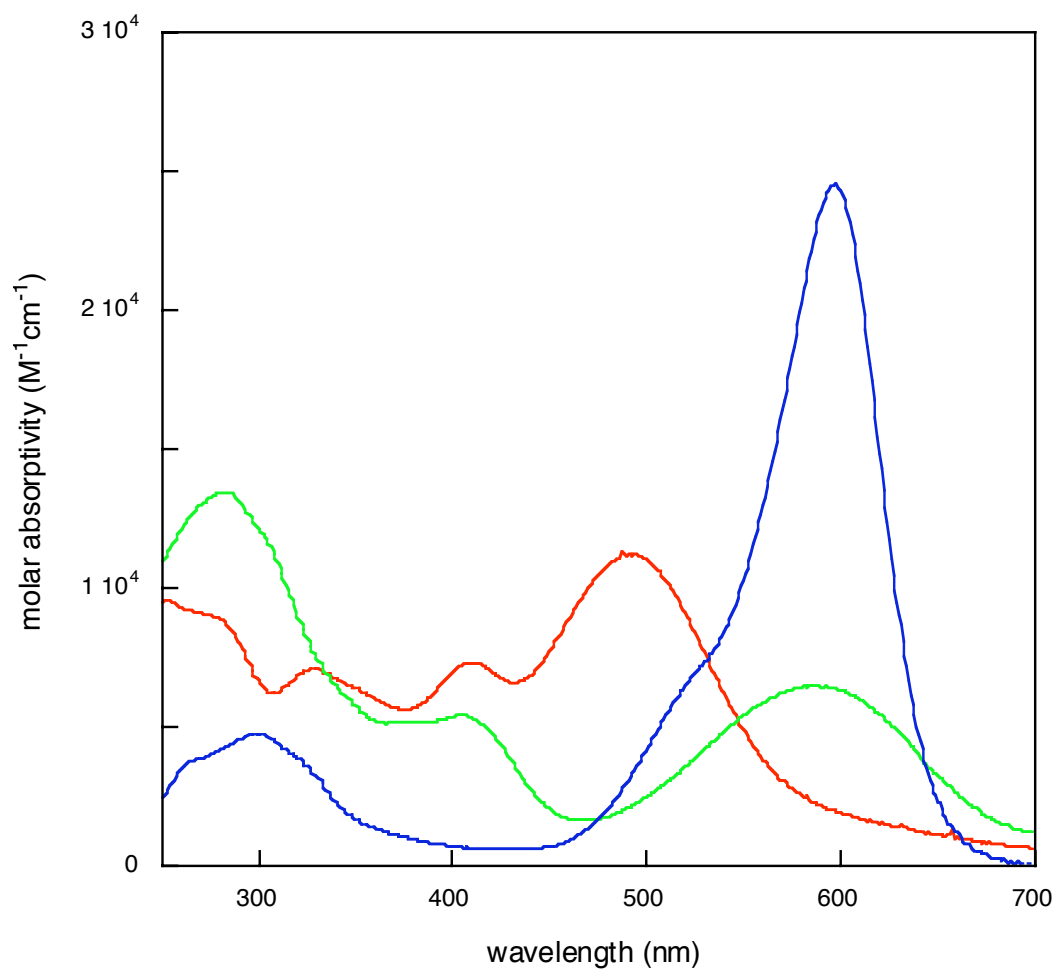

Figure S2. Absorption spectra for $\mathrm{TpOs}(\mathrm{NHPh}) \mathrm{Cl}_{2}$ (1) (red), TpOs[NH- $p$ $\left.\mathrm{C}_{6} \mathrm{H}_{4}\left(\mathrm{~N}\left(\mathrm{CH}_{2}\right)_{4}\right)\right] \mathrm{Cl}_{2}(3)$ (blue), and [TpOs( $\left.\left.\mathrm{NHPh}\right) \mathrm{Cl}_{2}\right]^{-}$(6) (green). The extinction coefficients for $\mathbf{5}$ are too small to give a significant spectrum on this scale. 


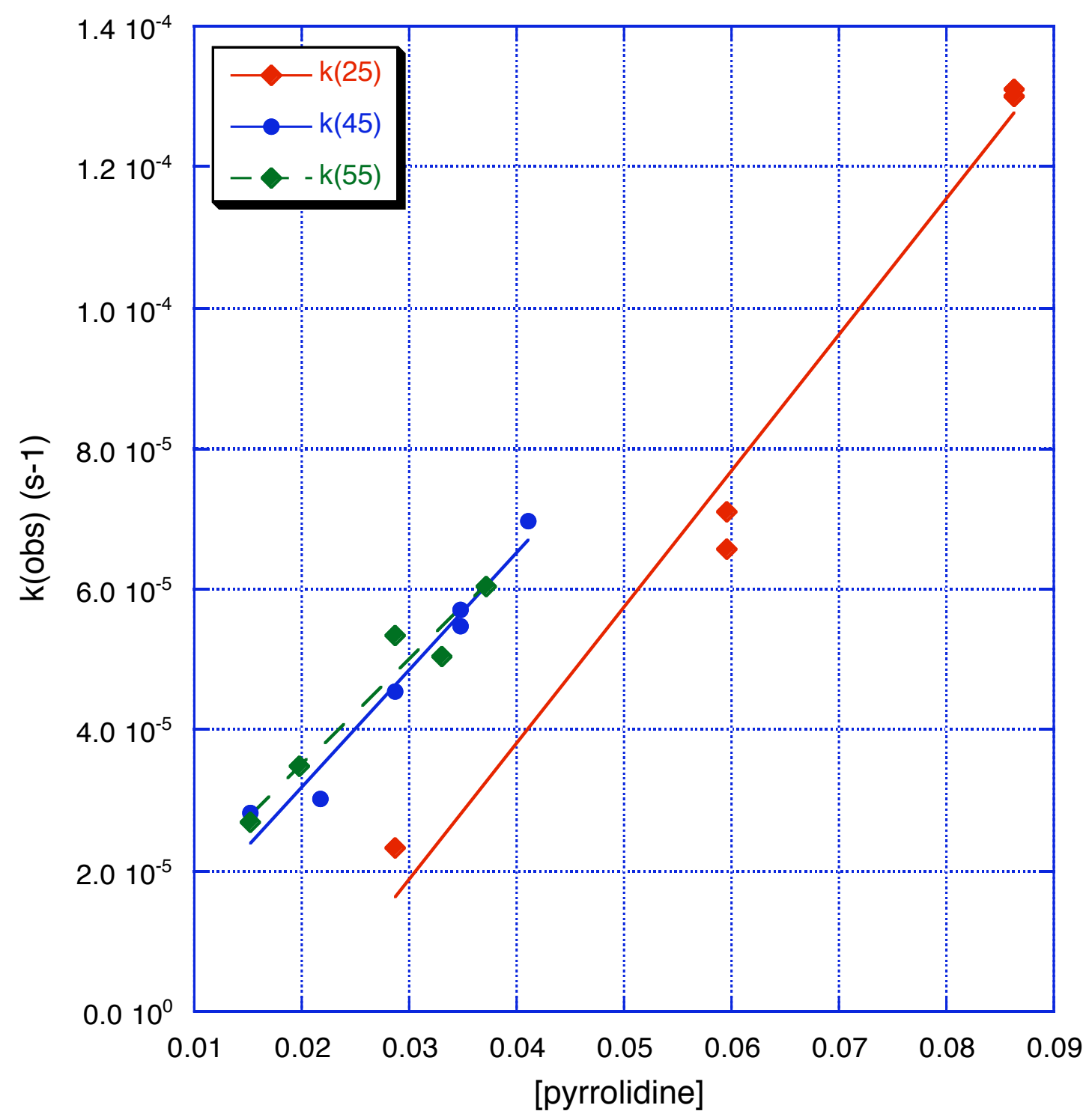

Figure S3. Plots of the observed pseudo-first order rate constant vs. [pyrrolidine] at three different temperatures. The equations of the lines are:
$25^{\circ} \mathrm{C}: k_{\mathrm{obs}}=-3.9 \times 10^{-5}+\left(1.9 \times 10^{-3}\right)^{*}$ [pyrrolidine]
$R^{2}=0.9813$
$45^{\circ} \mathrm{C}: k_{\mathrm{obs}}=-1.4 \times 10^{-6}+\left(1.7 \times 10^{-3}\right)^{*}$ [pyrrolidine]
$R^{2}=0.9620$
$55^{\circ} \mathrm{C}: k_{\mathrm{obs}}=5.4 \times 10^{-6}+\left(1.5 \times 10^{-3}\right)^{*}$ [pyrrolidine]
$R^{2}=0.9415$

The $k_{\text {obs }}$ value at $25^{\circ} \mathrm{C}$, [pyrrolidine] $=0.11 \mathrm{M}$ is above the red line shown and has been omitted. Including this point, gives $k_{\mathrm{obs}}=-5.0 \times 10^{-5}+\left(2.1 \times 10^{-3}\right) *$ [pyrrolidine] $\left(R^{2}=\right.$ 0.9778). Attempts to fit these data with a rate law second-order in [pyrrolidine] were unsuccessful. Also omitting the value at [pyrrolidine] $=0.086 \mathrm{M}$ gives $k_{\mathrm{obs}}=-1.9 \times 10^{-5}$ $+\left(1.4 \times 10^{-3}\right)^{*}$ [pyrrolidine] $\left(R^{2}=0.9897\right)$. A rate constant of $(1.7 \pm 0.4) \times 10^{-3} \mathrm{M}^{-1} \mathrm{~s}^{-1}$ is reported. 
